\title{
O PORTUGUÊS COMO LÍNGUA DE HERANÇA EM MUNIQUE: OFERTAS, PRÁTICAS E DESAFIOS
}

\section{Camila Lira*}

RESUMO: Munique é uma cidade multicultural. Dados do departamento de estatística da cidade apontam para um número grande de imigrantes morando na cidade, dentre eles 2417 brasileiros. Alguns dos motivos destacados para a presença deste na cidade são casamentos binacionais, reunião familiar, trabalho e estudos. A oferta de atividades culturais na cidade para falantes de Português também é destacada na gastronomia, na cultura e vem crescendo no que diz respeito ao ensino de Português para falantes de Herança, tanto em contextos formais como informais. Este artigo tem como objetivo mapear as ofertas de Português como Língua de Herança na cidade, bem como identificar os sujeitos participantes das atividades ofertadas com suas motivações, além de apresentar perspectivas e desafios para o fomento destas ofertas.

PALAVRAS-CHAVE: Cultura; Identidade; Português como Língua de Herança

\section{Introdução}

Com a mobilidade causada pela globalização mundial, pode-se notar nos últimos 10 anos um crescente fluxo de emigrantes brasileiros em países como Estados Unidos, Inglaterra, Portugal, Espanha, Japão, Alemanha, entre outros. Segundo pesquisa do Ministério de Relações Exteriores do Brasil, em 2015 foram contados 85.272 brasileiros residindo na

* Mestre em Alemão como Língua Estrangeira pela Universidade Ludwig Maximiliam de Munique (LMU). Doutoranda em Linguística pela Europa Universität Viadrina. 
Alemanha, dos quais cerca de 40.000 na Baviera e em Baden Württemberg, sem considerar aqueles com dupla nacionalidade. Fauss (2005, p. 9) afirma que a maioria dos brasileiros vivendo na Alemanha é formada por mulheres que vivem numa relação bilíngue, seguidas por trabalhadores, estudantes e Au-pairs. A maioria destes expatriados procura cultivar seus laços culturais com o país de origem, neste caso o Brasil, através da formação de redes sociais que propiciam encontros e vivências na sua língua e cultura. Segundo Lico (2011, p. 2), é inerente o desejo do emigrante em "manter vivos no seio de suas famílias os vínculos com as origens e cultura brasileiras", pautado em diferentes objetivos, como por exemplo, preparar-se para um possível retorno ou manter o contato com a família que ficou no país de origem.

É neste contexto sociocultural que se desenvolvem novas formas de linguagem, como é o caso das línguas de herança. Embora muito pesquisado nos Estados Unidos e Canadá, o termo língua de herança aparenta ser relativamente novo para a pesquisa de linguística aplicada relacionada à Língua Portuguesa. Segundo Valdés (2000), língua de herança $(\mathrm{LH})$ define uma língua falada em sua maioria em ambiente doméstico, que é diferente da língua dominante na sociedade local. Ainda neste contexto Van Deusen-Scholl (2003, p. 221) define os falantes de LH como pessoas que podem falar fluentemente a língua ou apresentarem apenas uma das competências linguísticas, ou serem bilíngues passivos que estão culturalmente ligados à língua. Dentro desta realidade pode-se encontrar o Português como língua de herança (POLH). Mendes (2012, p. 21) afirma que "o português como língua de herança (PLH) caracteriza-se pelos contextos em que o português e sua cultura são ensinados a filhos de luso-falantes imigrados, em diferentes partes do mundo e representantes de diferentes línguas-culturas em português”. Estes contextos mencionados pela autora podem ser tanto familiar, escolar ou comunitário, dependendo também das relações identitárias que a família tem com a sua língua.

Haja vista o fato de um falante de LH ser um sujeito aprendiz de uma língua minoritária, é necessário analisar e compreender as tensões e relações que emergem deste indi- 
víduo, como é a sua percepção da realidade, o contato e a interação com a cultura dominante e com a minoritária, bem como qual é sua percepção da língua maioritária e da LH. Assim, é preciso buscar elementos que possam esclarecer ao falante que a LH faz parte de sua identidade, mesmo que ele não se declare como brasileiro (Moroni, A. \& Azevedo Gomes, J., 2015, p. 23).

Por estarem intimamente ligadas, é necessário observar como é a formação da identidade destes indivíduos e quanto esta é influenciada pela sua família e pelas políticas linguísticas adotadas por ela. Assim é necessário também levar em consideração o conceito de identidade descrito por Hall (2005), a qual observa que no mundo atual já não existem identidades fixas, mas múltiplas e também passar a analisar o conceito de identidade híbrida, para entender a importância da identidade cultural na língua de herança. Além disso, Turner \& Tajfel (1986) argumenta em sua Teoria da Identidade Social que membros de diferentes grupos minoritários se relacionam com a sociedade hospedeira em três formas: tentando assumir características locais, rejeitando normas da sociedade ou reforçando suas próprias características e adquirindo algumas da sociedade em que está inserido. Moroni \& Azevedo Gomes (2015, p. 24) afirmam ainda que a política linguística de famílias bi- ou multilíngues estão ligadas ao "contato e interação com a cultura dominante e a cultura da família e como este sujeito percebe a língua do entorno e da língua de herança”. Esta informação alia-se a fatores que segundo as autoras poderão influenciar a fluência na LH, como o uso da língua na família ou presença de uma comunidade de fala mais ampla e a oferta de cursos na LH.

Diante deste cenário e de acordo com o informe da Unesco Educaşão em um mundo plurilingue (2003), o qual manifesta a importância do uso da língua de herança e também aponta para a conscientização da família em relação aos benefícios de transmitir sua língua, este artigo objetiva analisar como as identidades linguística e cultural dos brasileiros residentes em Munique são influenciadas por sua migração e por sua relação com a sociedade em que está inserido bem como observar as ofertas de ensino e promoção do POLH na cidade. Para tanto, analisamos os dados colhidos com a comunidade brasileira através de 
questionário semiaberto e de entrevistas semiestruturadas. Com base nos resultados desta pesquisa, busca-se traçar as práticas, ofertas e desafios do ensino de POLH em Munique.

\section{Português como Língua de Herança}

Dentre os muitos conceitos utilizados para definir Língua de Herança (LH), todos têm em comum o fato de ver o falante de língua de herança (FLH) como uma pessoa que fala uma língua em ambiente familiar diferente da língua dominante do local onde vive. Cummins (2005, p. 586) define o FLH como aquele que possui uma língua diferente do inglês em ambiente familiar, advinda dos seus ancestrais. Aliado a este conceito, alguns autores veem a LH como um conceito sociocultural, cuja função é a de preservar não só a língua como a cultura de onde a família é proveniente (HE, 2010). Cabe ainda ressaltar que, dependendo do valor social dado a esta língua na sociedade onde o FLH está inserido, esta pode se tornar motivo de orgulho ou de afastamento, uma vez que a construção da identidade do indivíduo também passa pela relação de poder entre as línguas, as quais ele domina.

Enquanto conceito sociocultural, a LH também propõe a análise, discussão e tomada de medidas políticas para sua manutenção. Estas políticas devem ser discutidas não só no contexto familiar e nas suas relações com a oferta de cursos, atividades culturais na comunidade onde se vive como também em ações governamentais que apoiem o ensino, a promoção e manutenção das LH. Em sua pesquisa, Soares (2012, p. 14) cita o fato de que há certa incongruência política entre o desejo de investir no futuro da nação desenvolvendo cognitivamente os indivíduos e as políticas governamentais que "desvaloriza(m) o ensinoaprendizagem, transmissão e legitimação" da LH. Envolta entre relações sociopolíticas e linguísticas, atribui-se á LH a participação num "processo dialógico de negociação de experiências sociais, culturais e linguísticas entre pais e filhos” (SOUZA, 2017, p. 51), cujo maior objetivo é vivenciar as heranças culturais e linguísticas de forma a aceita-las, modifica-las e sentir-se parte delas.

Diante destas definições surge o Português como Língua de Herança (POLH), caracterizado pelo ensino do Português e pela transmissão da cultura brasileira para filhos de 
brasileiros nascidos ou residindo no exterior, como define Lico (2011). Dada as características deste aprendizado, Moroni e Gomes (2015) apresentam o ensino de POLH numa "abordagem interdisciplinar", tendo em vista as "questões de identidade, sociais, políticas e ideológicas" que permeiam a transmissão do POLH em seus diversos contextos mundo afora. Assim, transmitir o POLH é mais do que uma ação formal de ensino (muitas vezes inexistente), mas um diálogo "entre (e pelos) pais e filhos no que tange suas experiências sociais, culturais e linguísticas (...) em seu país de origem e o país de acolhimento" (SOUZA, 2017, p. 75).

De acordo com estudos de Jouët-Pastré (2011) o número de falantes de POLH até o ano de sua pesquisa nos Estados Unidos era quase inexistente em relação a falantes de outras línguas de herança. Porém nota-se um crescimento deste número de falantes e da preocupação das famílias em manter o POLH. Se olharmos para as redes sociais ${ }^{1}$ criadas nos últimos dois anos em prol do POLH, conseguimos notar este crescimento através da criação de grupos, eventos, simpósios e lançamentos de livros sobre o tema. Souza e Lira (2017) reuniram em seu livro O POLH na Europa algumas das iniciativas atuantes no continente europeu, destacando uma das características do ensino de POLH, que é ser organizado "a partir de iniciativas de pais e educadores (...) que entendem a necessidade de manter os laços linguísticos e culturais com suas origens" (SILVA, 2017, p. 205). Somente na Alemanha, por exemplo, podem-se listar grupos em Berlim, Dresden, Hamburgo, Colônia, Frankfurt e Munique. Esta última cidade viu duplicar o número de grupos em prol do POLH nos últimos anos. A oferta destes grupos passa desde encontros informais de mães e pais com brincadeiras dirigidas, mala de leitura a cursos de língua e cultura, sendo oferecidas por profissionais da área de Letras e Pedagogia como também por pais e interessados.

${ }^{1}$ Algumas das iniciativas espalhadas pelo mundo são citadas na página oficial do Ministério de Relações Exteriores do Brasil. 


\section{A comunidade brasileira em Munique}

Segundo pesquisa do Ministério de Relações Exteriores do Brasil, em 2015 foram contados 85.272 brasileiros residindo na Alemanha, dos quais cerca de 40.000 na Baviera e em Baden Württemberg, sem considerar aqueles com dupla nacionalidade. Especificamente na cidade de Munique, estão registrados oficialmente na cidade 2.417 brasileiros, dos quais 1563 são mulheres e 854 são homens, indo de encontro à pesquisa de Fauss (2005), a qual afirma que a maioria dos brasileiros vivendo na Alemanha é formada por mulheres que vivem numa relação bilíngue, seguidas por trabalhadores, estudantes e Au-pairs. Esta afirmação pode ser confirmada tanto pelo departamento de estrangeiros como em minha pesquisa sobre as ofertas para e da comunidade brasileira em Munique no ano de 2015, expressa no gráfico abaixo. Nele podemos observar que enquanto para os homens, trabalho e estudos são os primeiros motivos, vemos que as mulheres citam em primeiro lugar o casamento seguido do trabalho, somando também a esta categoria a categoria de Au-pair. Outros motivos como ter parentes na cidade e fazer tratamento médico também foram citados.

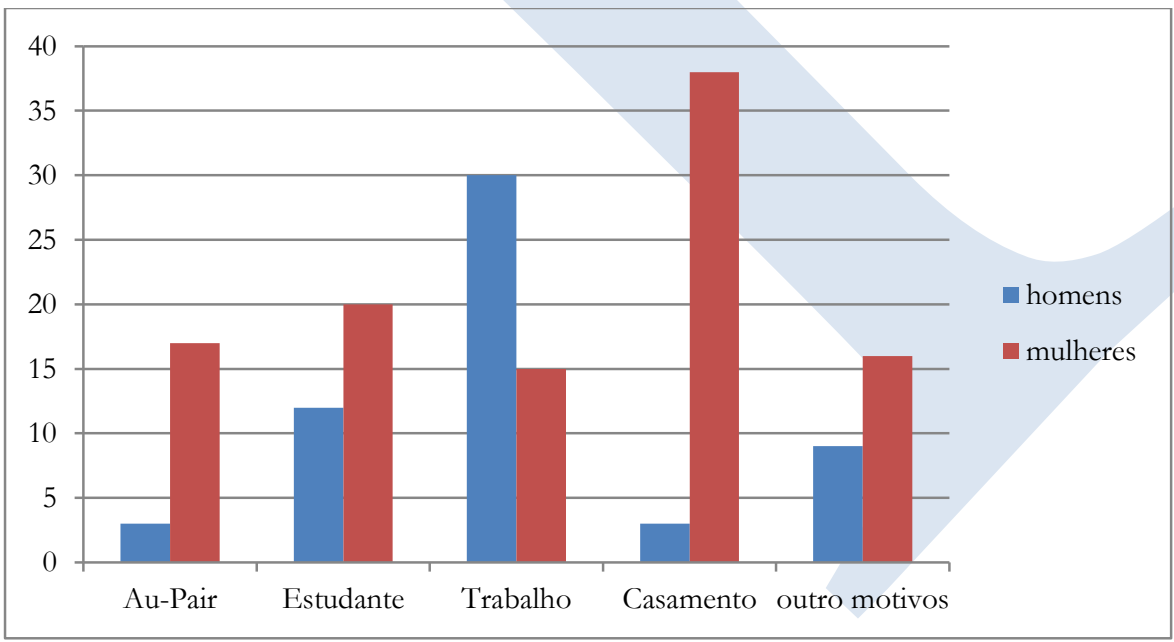

Gráfico 1 - Por qual motivo você veio morar em Munique? Fonte do autor 
Levando em consideração que os casamentos são um dos motivos de maior vinda de brasileiros à Munique, é interessante notar como é o perfil familiar dos entrevistados. A maioria das famílias são uniões biculturais, especialmente entre brasileiros e alemães. Porém, quanto menos tempo de residência na cidade, maior é o número de uniões monoculturais conforme o gráfico 2 .

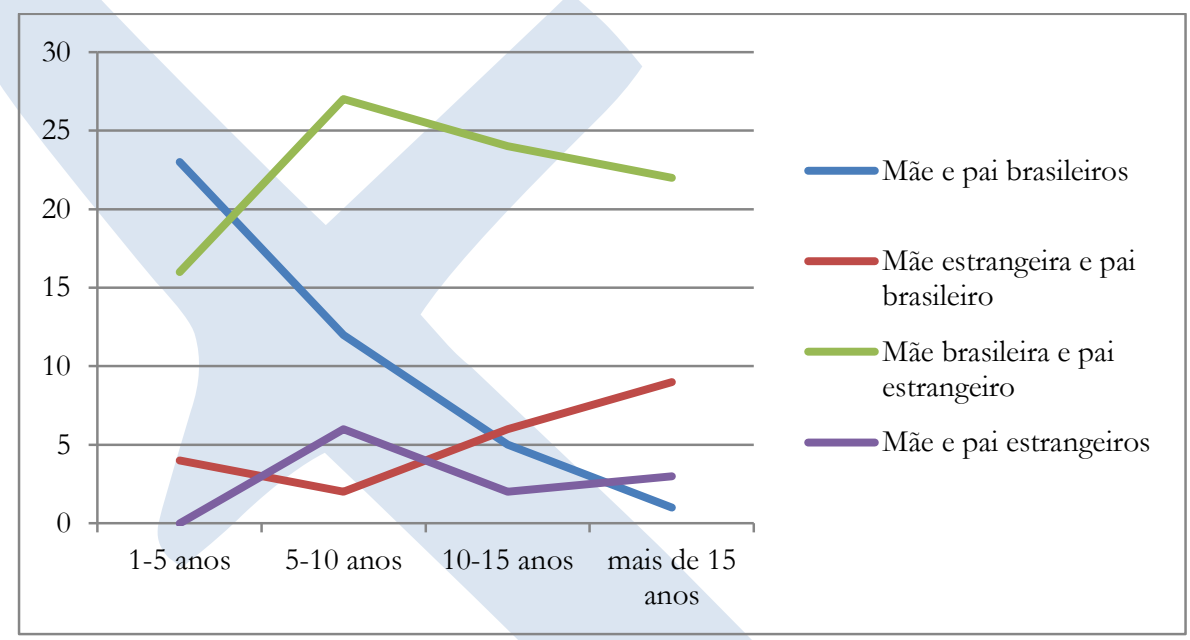

Gráfico 2 - Relação das uniões familiares com o tempo de residência em Munique Fonte do autor

Outro fator importante é o número de filhos destas famílias, as quais têm uma média 1,2 filhos, a mesma média encontrada por mim em pesquisa publicada em 2017 (LIRA, 2017, p. 283). Em sua maioria, estas crianças estão no início de sua fase escolar (jardim de infância e primeira e segunda série do ensino fundamental).

Diante desse perfil da comunidade brasileira, percebe-se que dado o número de crianças em fase escolar, se faz importante pensar nas ofertas para o ensino e manutenção da língua portuguesa e cultura brasileira para estas famílias. Além disso, também é importante analisar qual a importância da língua e da cultura para estes brasileiros, especialmente no que tange a inserção de seus filhos em sua identidade linguístico-cultural. 
Relacionando essa amostra de perfil da comunidade brasileira com as descrições familiares de Romaine (1999), nota-se que as estruturas familiares mais recorrentes encaixam-se em 3 das 5 categorias descritas pela autora:

1. Famílias binacionais cujos pais têm diferentes línguas e possuem certo grau de proficiência na língua do cônjuge. A língua dominante é também a língua de um dos pais. É o caso das famílias de pais alemães e mães brasileiras, língua da comunidade é o alemão.

2. Famílias monolíngues, cujos pais falam uma língua diferente da língua local. É o caso das famílias de pai e mãe brasileiros residentes na cidade onde a língua comunitária é o alemão.

3. Famílias binacionais e bilíngues, cujos pais falam línguas diferentes entre si e que também difere da língua local. Exemplo são as famílias de pai italiano e mãe brasileira e a de pai brasileiro e mãe norueguesa vivendo em Munique.

Cada uma dessas constelações familiares aqui descritas podem apresentar diferentes estratégias para o uso e a promoção da(s) língua(s) e da(s) cultura(s) em suas famílias. Importante é ressaltar que o desejo de que seus filhos se comuniquem em sua língua materna (LICO, 2011) torna-se um elemento motriz para a busca e ofertas de atividades em Português na cidade onde vivem.

\section{Munique e suas ofertas}

A cidade de Munique, capital da Baviera, é uma cidade multicultural. Basta andar por suas ruas para notar a diversidade linguística e cultural que ela abriga, sem falar no número elevado de turistas que a visitam todos os anos. Porta de entrada da região sul da Alemanha, sua proximidade com a Áustria e a Itália também facilita o seu desenvolvimento econômico. Assim, muitas empresas mundialmente conhecidas têm suas sedes ou filiais na cidade. Sua infraestrutura permite que os espaços públicos sejam bem utilizados por todos, 
para eventos culturais de diversos estilos. Também por isso encontram-se na cidade diversas associações ${ }^{2}$ sem fins lucrativos com ofertas culturais advindas dos locais onde seus fundadores vieram. A cultura brasileira e a Língua Portuguesa são divulgadas por mais de 35 associações, considerando aqui o grande número de grupos organizados de capoeira espalhados pela cidade. Dentre estas, destacam-se a DBKV - Deutsch-Brasilianischer Kulturverein (DBKV) e a Casa do Brasil e.V., com ofertas culturais como shows, teatro, debates e até uma biblioteca para seus sócios. Não se pode também deixar de falar da Mostra Brasil de Cinema, que acontece a cada biênio, seguida pelo Cinema Brasileiro em Munique, que oferece filmes à comunidade durante todo o ano.

Com relação à Lingua Portuguesa, destacam-se o jardim de infância Estrelinha e.V. e a associação Linguarte e.V., que trabalham com o ensino do Português Brasileiro nas últimas duas décadas, além do Grupo Pica-Pau Amarelo, que funcionou de 1988 até meados de 2015. O Pica-Pau Amarelo foi uma atividade proposta pela DBKV para crianças que tinha "como meta transmitir o português e a cultura brasileira a crianças teuto-brasileiras através de workshops de música, literatura infantil, pintura e trabalhos manuais"3. Suas atividades eram oferecidas em espaço cedido pela Missão Portuguesa da Igreja Católica na cidade durante a semana, por 90 minutos.

Já o Estrelinha surgiu da necessidade dos pais em manterem o português de seus filhos não só em casa, mas em algum espaço que permite o diálogo com pessoas na mesma situação. Para eles, o desejo de preservar suas raízes e de fornecerem aos seus filhos "um ambiente de aprendizado e convivência coletivos" (LICO, 2011), onde pudessem ter contato com outras crianças na mesma situação linguística, era o motor para a organização de um grupo de brincadeiras que começou a funcionar na casa de algumas famílias, passando por alguns endereços até chegar no local atual. De um grupo de brincadeiras, logo tornouse um jardim de infância com turmas de maternal, educação infantil e acompanhamento

${ }^{2}$ Uma lista dessas associações pode ser consultada no site da cidade de Munique: https://www.muenchen.de/freizeit/vereine.html

${ }^{3}$ Trecho retirado do site da associação em: http://dbkv.de/grupo-pica-pau-amarelo.php 
escolar, que é referência para a cidade e para outras iniciativas de Português no mundo. Com o intuito de ensinar não só a língua e a cultura alemã, a iniciativa de pais possui um conceito pedagógico abrangente visando ao desenvolvimento social, desenvolvimento da linguagem, formação musical e esportiva, dentre outros, contando com professores brasileiros e alemães para oferecerem as atividades de forma bilíngue.

Considerando a fundação das associações na cidade, pode-se dizer que a Linguarte surgiu 5 anos depois do Estrelinha para suprir de certa forma as mesmas necessidades de um outro grupo de brasileiros residentes em Munique. Fundada em 2003 por um grupo de pais para oferecer aulas complementares de Português, esta associação "concentra-se, primeiramente, em atividades que possibilitem a educação e o ensino de português aos filhos de falantes de Língua Portuguesa”, as quais possuem “conteúdos específicos do currículo brasileiro", projetos interdisciplinares e culturais, entre outros (LIRA, 2017, p. 280). Enquanto aulas extracurriculares, as aulas da associação aconteciam em escolas secundárias sempre que houvesse 10 alunos inscritos no curso. Diferentemente do Estrelinha, a associação focou seu trabalho em atividades do período vespertino, mudando a oferta para os sábados, quando não pode mais utilizar as salas das escolas da cidade devido a resolução estadual de 2008, de priorizar os cursos de Alemão como Língua Estrangeira em detrimento das aulas de Língua de Herança. Assim, a associação passou a oferecer suas atividades em centros de convivência juvenis, mantendo um valor mínimo de mensalidade. Seu currículo procura focar no trabalho da aquisição do POLH em suas competências oral, auditiva, de leitura e interpretação e escrita, na conscientização sobre a importância da LH e na promoção de contato com a língua e a cultura brasileira. (LIRA, 2017, p. 281) Além das aulas em seu formato formal, ainda se oferecem atividades de culinária, festas culturais (como a festa junina e o carnaval), além de passeios a locais onde possam construir o saber na LH. A iniciativa procura ainda fornecer ferramentas linguísticas aos alunos, seja pela diversidade linguística dos professores de diversas regiões do país como também a oferta de material de outros países lusófonos. Hoje com 7 turmas, a Linguarte tem atividades para bebês e suas mães a partir de 6 meses até adolescentes. Sua proposta baseia-se na linguística 
contrastiva, possibilitando ao aluno "analisar, vivenciar, contrastar e aplicar os conhecimentos adquiridos na sua língua dominante e ajustá-los aos diferentes usos na língua de herança” (LIRA, 2017, p. 282).

Também não podemos deixar de citar que o Consulado Português oferece aulas de Português em uma escola na região leste da cidade, sendo esta gratuita e aberta a todos os lusófonos. Seguindo um currículo desenvolvido para o ensino de Português no estrangeiro - QUAREPE, as aulas têm uma estrutura formal e podem ser inclusas no boletim do aluno. Apesar disso, nos últimos anos observou-se uma notável queda na procura deste curso.

Além destas atividades, nos últimos cinco anos notou-se o surgimento de grupos com o objetivo de estimular o convívio com a língua e cultura brasileira na cidade, como a Mala de Herança, o Quintal Brasil e encontros de pais e filhos em duas associações de bairros da cidade. Estes grupos, em sua maioria organizados por mães, priorizam a troca de livros e a leitura e a musicalização em português desde a mais tenra idade.

\section{Praticar o Português - estratégias familiares e comunitárias}

Pensando nas ofertas citadas neste artigo, aferimos que a cidade de Munique possui diferentes formas de se praticar o Português e vivenciar a cultura, seja no ensino formal como no informal. De fato, estas ofertas são diversificadas, bem estruturadas e bem localizadas. Lico (2011) refere-se ao senso de comunidade para creditar o sucesso das ofertas de POLH no exterior, sendo fundamental que a comunidade una-se em prol da conscientização de que a LH não é apenas a língua da família, mas tem um "sentido completo quando situada num ambiente mais amplo".

Assim, a união de brasileiros em torno de grupos associativos mostra-se um modelo capaz de reproduzir dentro da comunidade no exterior a cultura e a língua do emigrante. Não somente grupos denominados culturais, como também religiosos e esportivos propagam valores linguísticos-culturais aos filhos de brasileiros vivendo no exterior. As vivências as quais estas crianças são expostas possuem, para os pais, um valor abstrato, de transmitir 
a sua identidade cultural aos seus filhos, além claro, dos fatores sociais que permeiam o aprendizado de uma LH.

Como descrito no tópico anterior, as ofertas em Munique apresentam diversos objetivos, desde lazer ao ensino formal do POLH. São cerca de 31 associações esportivas, 4 culturais e 2 de ensino da língua e da cultura, além das religiosas, que deveriam atingir um número grande de brasileiros e/ou lusófonos. Porém, dados de pesquisa realizada com a comunidade em 2015 mostram que são poucos os que conhecem todas as ofertas. Dos 163 participantes, cerca de 48\% dos participantes afirmam conhecer atividades para a promoção do POLH, um número relativamente baixo, considerando a gama de iniciativas existentes. Interessante é notar que o grupo que conhece alguma oferta cita praticamente todas elas em suas respostas, como por exemplo este participante:

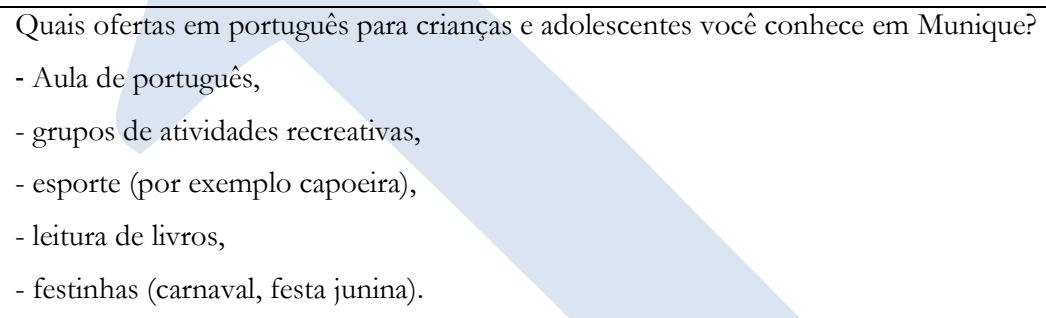

Figura 1 - Trecho da pesquisa realizada com a comunidade brasileira em Munique Fonte: Questionário fornecido pelo autor

Vale ressaltar ainda que as ofertas confundem-se com seus idealizadores, fazendo com que alguns participantes citem o nome de quem oferece, mas não o que realmente oferecem.

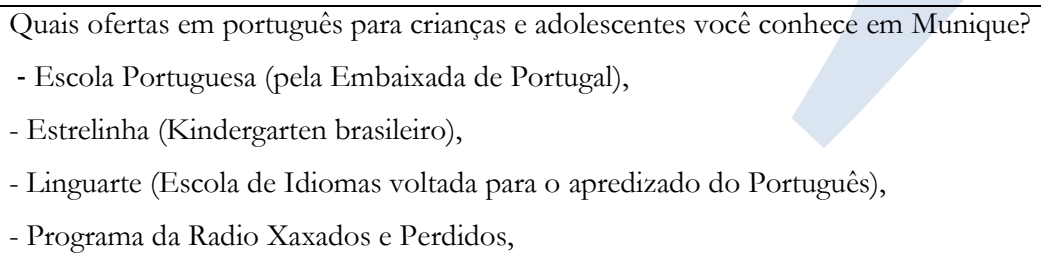


- Casa do Brasil (+com biblioteca comunitária),

- Teatro Ricardo Eche

Figura 2 - Trecho da pesquisa realizada com a comunidade brasileira em Munique Fonte: Questionário fornecido pelo autor

Os dados colhidos em questionário semiestruturado mostram ainda que os participantes conhecem as atividades propostas pela comunidade, mas não participam delas. Muitos justificam a sua falta de participação com fato de nunca saberem dos eventos ou de sempre descobrirem as atividades quando estas já aconteceram. Há ainda aqueles que indicam ser um problema a data, local e o horário das atividades.

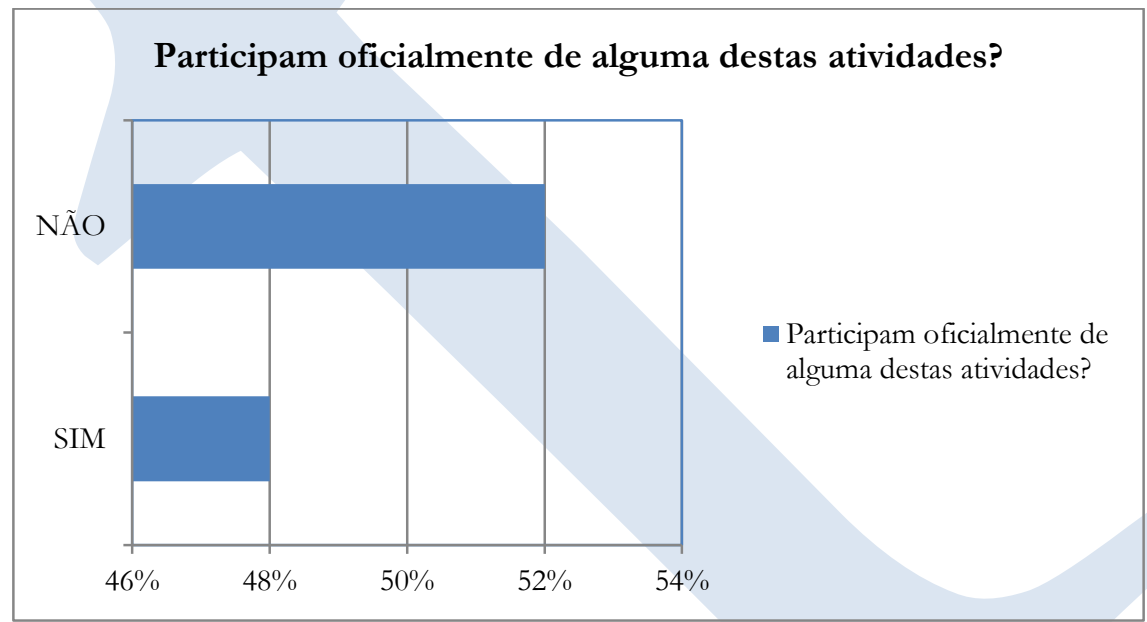

Gráfico 3 - Participação nas atividades de POLH da comunidade Fonte: Questionário fornecido pelo autor

Por outro lado, os organizadores de tais atividades procuram divulgar seus eventos através de mala direta, facebook, distribuição de flyers em locais estratégicos e do boca a boca, de forma a atingir o maior número possível de interessados. De fato, esta estratégia parece ter o efeito esperado se consideramos que o número de entrevistados que conhecem as atividades é muito próximo daqueles que as desconhecem. 
Cabe ainda ressaltar que os frequentadores destas ofertas consideram-nas ótimas ou boas, destacando-se a importância delas para manter a nossa cultura e para que as crianças tenham oportunidade de aprender o idioma de origem dos pais, compreenderem seus costumes, suas raízes. Ainda afirmam ser importante para que possam ter um bom contato com a família no país de origem, e principalmente para que tenham um idioma a mais que pode ser aprendido dessa forma facilmente e que os diferencia de outros com apenas um idioma, conforme cita um dos entrevistados.

Observando os fluxos participativos nas atividades, pode-se notar que a comunidade brasileira em Munique é organizada, oferecendo atividades de qualidade a seus participantes. Além disso, a preocupação com a qualidade destes eventos é presente na organização dos mesmos, na realização de eventos como a leitura de livros, cujo objetivo é o de "estimular a leitura entre as crianças, a interação com os pais e, acima de tudo, possibilitar a expansão do vocabulário de cada criança na língua portuguesa” (MENESCAL HEATH, 2017, p. 22). E também pode ser notado na pesquisa de músicas e brincadeiras folclóricas a serem apresentadas bem como na organização de cursos para professores de POLH. Estes últimos têm papel importante na grade acadêmica da Linguarte, que os considera importante para entender o bilinguismo e estimular atividades e diálogos entre pais e professores, mantendo-os assim participativos (LIRA, 2017, p. 283). Esta associação, além de oferecer formação pedagógica anualmente para seus professores e associados, já organizou, juntamente com a Mala de Herança e com a Casa do Brasil e.V., alguns cursos e oficinas para professores de POLH, recebendo participantes da Europa e do Oriente Médio.

Aliados a estas ofertas comunitárias, faz-se necessário entender os movimentos em prol da manutenção do POLH nas famílias. Em sua maioria, os participantes assumem um papel de mediador do conhecimento, oferecendo aos filhos Cds, DVDs, filmes e livros na língua minoritária. Alguns ainda citam os jogos como material relevante em seu acervo. O contato com a família é um dos maiores motivos para se manter o português e por isso, conversas via telefone ou Skype são elementos importantes na vida cotidiana. Interessante é notar que o contato com outras variantes do Português tem um papel pequeno se o 
considerarmos um elemento de promoção do POLH na cidade. Isso se dá porque muitos dos entrevistados ainda veem a variante europeia com certo preconceito, alegando não compreenderem o que falam ou simplesmente falta de conhecimento das ofertas destas comunidades em prol do POLH. Apesar disto, algumas famílias inscrevem seus filhos nos cursos de Língua e Cultura do Consulado Português, por acreditarem que isto também trará benefícios para seus esforços. É como argumenta o participante a seguir:

Levaria o seu filho a um evento ou a aulas de português cuja variante não é a falada por sua família?

Claro que sim, pois sem duvida quanto maior e mais abrangente for a formação e a cultura dos nossos filhos, melhor. Além disso, em relação à escala global, isso só traz vantagens.

Figura 3 - Trecho da pesquisa realizada com a comunidade brasileira em Munique Fonte: Questionário fornecido pelo autor

Para além destes fatores positivos de ofertas e práticas comunitárias e familiares, ainda notamos que há um certo desconhecimento por parte dos participantes de seus direitos enquanto falante de uma LH, o que se coloca como um dos desafios a serem descritos no próximo tópico deste artigo. Esse desconforto pode ser observado através deste trecho:

IMPORTANTE: Gostaria de saber, se possível, porque é que alunos alemães (descendentes de portugueses ou brasileiros por parte de mãe, pai ou ambos), quando fazem o ABITUR aqui na Baviera (não sei das regras em outras regiões), a Lingua Portuguesa não é aceita como uma Lingua estrangeira "para o ABITUR". Sei que os turcos podem fazer o abitur optando pela lingua turca como lingua estrangeira. A gente investe tantos anos levando e buscando as crianças para a escola portuguesa, e no final, isso não é considerado aqui. Não entendo, ou não sei se estou mal informada. REPASSO A DÚVIDA.

Figura 4 - Trecho da pesquisa realizada com a comunidade brasileira em Munique: dúvidas Fonte: Questionário fornecido pelo autor 


\section{Percursos e recursos para o POLH em Munique}

Observando os dados obtidos com o questionário aplicado nesta pesquisa, podemos notar que apesar da grande oferta de atividades para o POLH, a comunidade brasileira ainda enfrenta alguns desafios para serem, de fato, implementadas e atingirem um número maior de brasileiros. Em artigo publicado sobre os desafios do ensino de POLH em Londres, Souza (2016) apresenta 7 questões determinantes enquanto desafios para o ensino de POLH, os quais também podem ser observados em Munique e em outros locais onde este é oferecido por iniciativas de promoção da língua e cultura brasileira. Associado à (1) falta de local adequado para o desenvolvimento das atividades, pode-se contar como desafio também a (2) falta de treinamento de professores, a (3) falta de um currículo inexistente para o ensino de POLH advindo do governo brasileiro bem como a (4) falta de material didático apropriado. Além desses fatores de cunho material e governamental, a autora cita ainda (5) a diversidade linguística dos alunos, (6) a motivação destes e de (7) suas famílias.

Analisando os dados obtidos para este artigo, nota-se que estes desafios se fazem presentes também nos discursos dos pais, especialmente com relação à formação dos professores e organizadores das atividades informais: para eles, o professor deve ter formação adequada para o ensino de português no exterior. Porém se for uma atividade informal (esportes, brincadeiras e encontros de pais e filhos), basta ter "carisma e serem conhecedoras dos temas apresentados". Outro fator importante na análise dos dados é que a motivação das famílias é maior quando estas não precisam necessariamente participar da organização dos eventos. Cabe ainda ressaltar que o papel das famílias em motivar seus filhos também é relevante em se tratando da participação em atividades de POLH: se os pais não demonstram interesse ou apenas enviam seus filhos a cursos, estes perdem o interesse pela sua LH. Além disso, a comunidade precisa começar a pensar em ampliar a oferta cultural em português, que tenha não só a criança como público-alvo, mas também o adolescente.

A realidade revela ainda que apesar de muitas famílias transmitirem as suas línguas de herança aos seus filhos, sendo para muitos a sua L1, a verdade é que ao atingir a fase escolar, pais e filhos acabam por não priorizar o ensino formal da LH, como relata Soares 
(2012), deixando de buscar as possibilidades existentes para formalizar o ensino na cidade. É o que ocorre em Munique e foi exteriorizado na figura 4. Neste caso, uma busca mais detalhada de informações mostraria que é possível fazer o Abitur em Português, entrando com um pedido formal na secretaria de educação.

Por fim, o POLH em Munique precisa abrir caminhos para dialogar com a sociedade e com as instituições governamentais não só em busca de apoio como também para suprimir o preconceito existente em algumas pessoas acerca do bilinguismo (LIRA, 2017). Além disso, a oferta de cursos e formação de profissionais de ensino de POLH deve ser diversificada, buscando atingir a todos os movimentos da cidade, desde os professores do jardim de infância aos professores das associações, além de abranger todas as variantes da língua.

\section{Conclusão}

Embora Munique reúna diferentes ofertas de POLH para a comunidade brasileira, ainda se enfrentam muitos desafios para sua promoção e manutenção. Os dados obtidos na análise do questionário trazem à luz as ofertas da comunidade para as famílias com crianças pequenas e até a fase escolar. Após esta fase, são poucos os eventos destinados aos adolescentes, aumentando novamente a oferta ao público adulto.

Analisando os discursos de sua comunidade, observa-se que as atividades oferecidas têm qualidade e reúnem diversas formas de estímulos ao POLH: de atividades informais como piqueniques, encontros de pais e filhos a atividades formais como contação de história e aulas de POLH. Porém, nota-se que apesar dos esforços da comunidade e dos organizadores destes eventos em atingir um público cada vez maior, apenas metade dos entrevistados conhecem e participam destes eventos. Embora existam agendas culturais divulgadas pela e para a comunidade através de órgãos oficiais (site do consulado, da prefeitura, etc.), facebook e site das associações, faz-se necessário buscar outros caminhos de contato com a população brasileira na cidade. 
Os dados revelam ainda que as famílias preocupam-se em manter o POLH em suas casas, procurando formas de interação social com a língua, seja através de mídias ou através do contato com a família residente no Brasil. Dessa maneira, os esforços familiares unemse às ofertas comunitárias, agindo para a preservação da língua e da cultura acerca da língua alemã, fazendo então do espaço linguístico de POLH na Alemanha um local de contato e interação entre as culturas da família e da sociedade (MORONI \& AZEVEDO GOMES, 2015). Esta interação contribui também para a formação da identidade do indivíduo, conforme Turner \& Tajfel (1986) e Hall (2005). Muito embora isto aconteça, algumas famílias ainda se deparam com percalços nos caminhos para a manutenção do POLH. Um deles é o fato da sociedade alemã ainda ter certos preconceitos com relação ao indivíduo bilíngue e seu desempenho na língua alemã. Outro fator importante é a falta de informação acerca das ofertas formais de ensino do POLH nas escolas, sendo incluso no boletim escolar ou aceito no Abitur, uma espécie de ENEM alemão.

Apesar destes problemas, percebe-se também intrínseco nos pais o desejo de manter viva a sua cultura e a língua. A transmissão do POLH não é vista como apenas a aquisição de vocabulário em Português, capaz de manter uma conversação com familiares, mas também como parte da formação identitária do indivíduo bilíngue, (como a definida por Hall e descrita no começo deste artigo) que vive entre o Brasil e a Alemanha e cujo sucesso no futuro, seja escolar ou até mesmo no mercado de trabalho, também advém da aquisição da LH. Deste modo, tanto família quanto os grupos que organizam atividades formais de ensino de POLH (o jardim de infância Estrelinha, a associação Linguarte, as aulas de língua e cultura do Consulado Português) na cidade de Munique buscam em cursos de formação, palestras, oficinas e eventos para professores, ampliar os conhecimentos pedagógicos e linguísticos acerca do que oferecem. Deste modo, a cidade viu-se nos últimos anos palco, numa visão macro, para o II-SEPOLH (Simpósio Europeu de Português como Língua de Herança), para oficinas internacionais como as oficinas do ELO Europeu de Educadores de POLH, além da oferta de reuniões pedagógicas e cursos internos que visam ao desenvolvimento e capacitação de seu quadro de professores. 
Por fim, o aumento na divulgação destas ofertas, a participação dos pais e o trabalho em conjunto com a comunidade e com os governos podem apontar para a solução dos desafios encontrados nesta pesquisa. Os dados aqui presentes servem para criar uma discussão com todos os envolvidos, buscando novos caminhos e trazendo mais resultados positivos a longo prazo.

\title{
PORTUGUESE AS HERITAGE LANGUAGE IN MUNICH: OPPORTUNITIES, PRACTICES AND CHALLENGES
}

\begin{abstract}
Munich is a multicultural city. Data from the city's statistical department point to a large number of immigrants living in the city, including 2417 Brazilians. Some of the reasons for their presence in the city are binational weddings, family reunions, work and studies. The offer of cultural activities in the city for Portuguese speakers' is also outstanding in gastronomy, culture and has been growing referring to the teaching Portuguese for Heritage speakers, in formal and informal contexts. This article has the objective of mapping the Portuguese as a Heritage Language offered in the city, as well as identifying the subjects participating in the activities with their motivations and presenting perspectives and challenges for the promotion of these offers.
\end{abstract}

KEYWORDS: Culture, Identity, Portuguese as Heritage Language

\section{REFERÊNCIAS}

BRASILEIROS NO MUNDO - estimativas populacionais das comunidades brasileiras no mundo. Disponível em: http://www.brasileirosnomundo.itamaraty.gov.br/a-comunidade/estimativas-populacionais-das-comunidades/Estimativas\%20RCN\%202015\%20\%20Atualizado.pdf Acesso em: 20 abr. 2018.

FAUSS, Monica. Brasilianer in Deutschland. In: Informativo 4, 1, S. 9. 2005. Disponível em http://www.dbkv.de/publikation/informativo_1_2005.pdf. Acesso em: 20abril.2018

HALL, S. A identidade cultural na pós-modernidade. Rio de Janeiro: DP\&A ed. 2005. 10. ed.

HE, A. Toward an identity theory of the development of Chinese as a heritage language. 2006. Heritage Language Journal. Vol. 4, $\mathrm{n}^{\circ}$ 1, 2006. Disponível em: http://www.heritagelanguages.org/ViewPaper.ashx?ID=e6YzJ530d\%2fzrgPgMlR5aaQ\%3d\%3d Acesso em 13 abri. 2018

JOUËT-PASTRÉ, Clémence. Mapping the World of the Heritage Language Learners of Portuguese: Results from a National Survey at the College Level. Portuguese Language Journal 5, 2011 Disponível em: http://rll-faculty.fas.harvard.edu/clemencejouetpastre/publications/mapping-world-heritage-language-learners-portuguese-results Acesso em 20 de maio de 2018 
LICO, Ana Lucia Cury. Ensino do Português como Língua de Herança: Prática e Fundamentos N. 2 V.1. 2011. Disponível em: http://www.siple.org.br/index.php?option $=$ com_content\&view $=$ article\&id $=177: 2$-ensino-do-portugues-como-lingua-de-heranca-pratica-e-fundamentos\&catid=57:edicao-2\&Itemid=92. Acesso em: 15 abr. 2018.

LIRA, Camila (2017) Linguarte e.V.: Contribuindo para o desenvolvimento do POLH na Alemanha. In: Souza, A. \& Lira, C. (Orgs.). O POLH na Europa. Vol.1. Londres, JN. Paquet, 2017, p. 281-290.

MENDES, Edleise. Vidas em Português: Perspectivas culturais e identitárias em contexto de Português como Língua de Herança (PLH) In: Platô 2, vol.1 S.22-31, 2012 Disponível em: http://issuu.com/platorevista/docs/praia-dez-2013-115paginas. Acesso em 14 de Abril 2018.

MENESCAL HEATH, Andréa. A Mala de Herança 2017. In: Almeida, S. \& Menescal Heath, A. Palavras herdadas: sobre o Português como Língua de Herança. São Luís, Edufma, 2017, p.

MORONI, A. \& AZEVEDO GOMES, J. O Português como Língua de Herança hoje e o trabalho da Assoçiação de Pais de Brasileirinhos na Catalunha. 2015, In: REB. REVISTA DE ESTUDIOS BRASILEÑOS, vol. 2, n. 2, 2015. p. 21-35 Disponível em: https:// reb. universia.net/article/view/1206/portugues-lengua-herencia-trabajo-associacao-pais-brasileirinhos-na-catalunha. Acesso em 23 junho 2018.

ROMAINE, Susanne. Bilingual Language Development. In: BARRET, M. The Development of Language. New York: Psychology Press. 1999, p. 251-276

SOARES, Sofia M. C. C. D. Português Língua de Herança: Da Teoria à Prática. 2012. $123 f$. Tese (Mestrado em Português Língua Segunda/Língua Estrangeira) - Faculdade de Letras, Universidade do Porto, Porto, 2012. Disponível em: https://cepealemanha.files.wordpress.com/2010/12/portuguecc82s_licc81ngua_de_heranccca7a_sofia_soares.pdf. Acesso em: 20 maio. 2018.

SOUZA, A. Is Brazilian Portuguese being taught as a Community or Heritage Language? In: Language Issues, Summer, vol 27, n.1. 2016, p. 21-28. Disponível em: https:/ / souzaana.files.wordpress.com/2017/04/souza-a-2016c-is-brazilian-portuguese-being-taught-as-acommunity-or-heritage-language.pdf Acesso em 19 mai. 2018.

SOUZA, A. O Ensino de Português Brasileiro na Inglaterra: Uma Língua de Herança ou Língua Comunitária? In: Souza, A. \& Lira, C. (Orgs.). O POLH na Europa. Vol.1. Londres: JN; Paquet, 2017. p. 51-68.

SOUZA, A. \& LIRA, C. (Orgs.). O POLH na Europa. Vol.1. Londres: JN; Paquet, 2017.

Statistisches Amt münchen. Die ausländische Bevölkerung nach der Staatsangehörigkeit 2017. Disponível em: https://www.muenchen.de/rathaus/dam/jcr:89a2dcdb-76bb427d-8930-61a956092c08/jt180115_korr.pdf Acesso em 20 março 2018. 
TURNER, J. C., \& TAJFEL, H. The social identity theory of intergroup behavior. Psychology of intergroup relations. Disponivel em: https://student.cc.uoc.gr/uploadFiles/\%CE\%92310/Tajfel\%20\&\%20Turner\%2086_SIT_xs.pdf. Acesso em 7. Junho 2018.

VALDÉS, G. Introduction. Spanish for native speakers. AATSP professional development series handbook for teachers. New York: Harcourt College.

VAN DEUSEN-SCHOLL, N. Towards a Definition of Heritage Language: Sociopolitical and Pedagogical Considerations. Journal of Language, Identity, and Education, 2(3), 211- 230. 2003. Disponível em http://eric.ed.gov/?id=EJ673151 Acesso em 21 maio 2018.

WERTHEIN, J. \& CUNHA, C. Fundamentos da Nova Educação. Cadernos Unesco, vol.5. 2000. Disponível em: http://unesdoc.unesco.org/images/0012/001297/12976 6por.pdf Acesso em 30. Junho 2018.

Recebido em: 13/05/2018. Aprovado em: 15/08/2018. 